\title{
DEL APRENDIZ DE BRUJO \\ A LA ESCALADA REFLEXIVA: \\ EL PROBLEMA DE LA HISTORIA \\ EN LA SOCIOLOGIA \\ DE NORBERT ELIAS
}

\author{
Ramón Ramos Torre
}

Universidad Complutense de Madrid

\begin{abstract}
born from a storm of disorder nomads of time without tiding in a void without border riding the storm.
\end{abstract}

(N. Elias, en Kilminster, 1991: XI.)

Toda tradición tiene su Juan Bautista, ese iluminado obsesivo e innovador que habla a los hombres de la ciudad con la ruda ira de los hombres del desierto. Hay siempre algo nuevo y viejo en él: la reiteración de las tradicionales verdades de la tribu y una nueva interpretación insospechada. Y su reconocimiento es tardío, como es de esperar de quien se sitúa entre dos mundos y participa confusamente de sus verdades incompatibles.

Norbert Elias es el Juan Bautista de la sociología histórica. En alguno de sus santorales todavía sigue sin figurar como tal, pero en otros ha conseguido ya su definitivo reconocimiento ${ }^{1}$. Y es justo que así sea porque su obra es pre-

${ }^{1}$ En el recuento de precedentes y representantes de la sociología histórica que aparece en el libro-manifiesto Vision and Method of Historical Sociology (Skocpol, 1984) todavía no aparece incluido en tan amplia y brillante compañía. Sí es reconocido como tal en el trabajo de Abrams (1982: 145-146, 231-239) y, de forma más explícita, en el de Smith (1991: 46-53). 
monición o anuncio tanto del proyecto en sus señas genéricas de identidad como de las dos variantes fundamentales en las que se ha encarnado (cfr. Ramos, 1993). Anuncia el proyecto en su genericidad porque la obra de Elias puede entenderse básicamente como la primera protesta seria contra lo que Zaret (1980) ha llamado el «eclipse de la historia» en la sociología, eclipse desastroso que Elias denunciaba como estéril «retirada del sociólogo en el presente» o insensata "fuga del pasado» (Elias, 1987b: 223). Pero también en su obra se puede encontrar un claro precedente de las dos variantes fundamentales de la sociología histórica: de la variante más radical y teóricamente más ambiciosa que quiere convertir el reencuentro con la historia en punto de arranque para una reorientación global hacia una nueva sociología episódica y narrativa ${ }^{2}$; y también de la variante más moderada y con mayor éxito institucional que, huyendo de la gaseosidad ahistórica de las teorías de la modernización y el desarrollo posteriores a la II Guerra Mundial, ha conseguido reintroducir en la experiencia intelectual del sociólogo «el placer de devorar libros de historia» (Mann, 1991: 9), renovando profundamente los estudios sobre el cambio social ${ }^{3}$.

La gloria y miseria de tan ilustre predecesor se cifra, con todo, en la paternidad de una única criatura; una criatura ciertamente extraña, semejante a un pulpo de mil tentáculos al que siempre le crecieran nuevos brazos. Me refiero, obviamente, al proceso de civilización. A él dedicó su primer gran libro (Elias, 1978 y 1982c) y a él también todas sus obras posteriores, reconducidas siempre a esa matriz básica, ya estudiaran la corte de Luis XIV (Elias, 1982a), los problemas de la teoría sociológica (Elias, 1982b), la vejez y la muerte (Elias, 1987a), la guerra fría (Elias, 1988), el deporte (Elias y Dunning, 1986), la vida de un genio musical (Elias, 1991a) o el viejo problema del tiempo (1989). En todos los casos, el objeto inmediato de estudio sólo cobraba nueva luz y accedía a su inteligibilidad sociológica gracias a sus conexiones con ese proceso multisecular que vertebra el desarrollo histórico. Esto explica tal vez su exacto estatuto de predecesor que se halla entre dos aguas. Pues la reivindicación de la historia iba en su caso de la mano de una sociología desarrollista con un fuerte "tufo» decimonónico que le creaba más enemigos que amigos: anunciaba algo nuevo pero sin renunciar a seguir llevando el viejo fardo de una ciencia social que todos declaraban y declaramos obsoleta ${ }^{4}$.

2 El proyecto arranca de Abrams (1982) y encuentra en los trabajos de Griffin (1992) y Abbot (1992) su expresión más radical. Cfr. el núm. 20 (4) de Sociological Methods and Research (1992), dedicado a la sociología histórica, y Ramos (1993).

${ }^{3}$ Se trata de la variante cuyos representantes más brillantes son Skocpol, Tilly y Mann, que, sin estar directamente influidos por Elias, han desarrollado su trabajo en la senda ya definida por El proceso de la civilización y La sociedad cortesana.

${ }^{4}$ En este sentido, Lasch (1985: 108) advierte que Norbert Elias «ha de ser leído no sólo como uno de los ejemplos de sociología histórica, sino también como la última de las grandes síntesis del siglo XIX». Bauman (1979: 120) destaca también con acierto su "conservadurismo revolucionario", enfrentado a las tendencias modernas de la sociología en reivindicación de la sociología clásica. 
El problema que voy a rastrear en este trabajo tiene este marco de inteligibilidad. Es el problema de la historia en la obra de un autor decisivo que siempre nadó entre dos aguas: por un lado, el legado proporcionado por la Gran Historia de la ciencia social decimonónica; por el otro, el proyecto renovador de un maridaje historiográfico-sociológico que atisbó pero no concretó. Para reconstruir este problema organizaré la exposición que sigue en tres partes. La primera analizará la crítica de Elias a la historiografía tradicional. La segunda abordará su crítica a la sociología ahistórica del siglo XX. La tercera reconstruirá el problema general de una historicidad planteada como un proceso que es direccional y ciego a la vez y tiene su expresión más exacta en el desarrollo civilizatorio.

En uno de sus planos estratégicos, la obra de Elias se desarrolla como una progresiva toma de conciencia de los efectos desastrosos que para la ciencia social ha supuesto el divorcio entre la sociología y la historia. Viviendo y trabajando de espaldas los unos a los otros, diagnostica Elias, «los historiadores no se preocupan lo suficiente por aclarar y precisar su aparato teórico y conceptual, y los sociólogos tampoco se esfuerzan bastante por elaborar teórica y conceptualmente los conocimientos históricos particulares que hoy en día son imprescindibles» (Elias, 1982a: 289). Surge así una historia teóricamente anémica de la mano de una sociología empíricamente inespecífica e indiferente a la dinámica social. Acabar con esa situación supone abogar por una mutua aproximación de las dos disciplinas que, aceptando que ambas «dirigen su atención únicamente a sustratos o planos diversos de una sola e idéntica relación histórica»(Elias, 1982a: 42), consolide una tupida red de conexiones mutuamente provechosas 5 .

La alternativa propuesta por Elias sólo puede consolidarse si se realiza una crítica sistemática a las pretensiones de una historiografía y una sociología empeñadas en extrañarse mutuamente. Reconstruiré y evaluaré a continuación la crítica a la historiografía, para abordar en el siguiente parágrafo la crítica a la sociología ahistórica.

La crítica eliasiana a la historiografía es una constante a lo largo de su obra, pero aparece de forma más sistemática en las páginas de la introducción a $L a$ sociedad cortesana (Elias, 1982a: 9-52). Aparentemente, es una crítica a la historiografía tradicional, ya que arranca de la evaluación del programa de Ranke (Elias, 1982: 13), pero en realidad se desarrolla como crítica a la historiografía tout court: la del siglo XIX y la del XX.

5 Elias no aboga por la disolución de las especializaciones disciplinares, sino por su coordinación, cifrando sus esperanzas de renovación en «un considerable cambio de orientación en las disciplinas especializadas actualmente sin conexión, aunque no, por supuesto, el final de la especialización disciplinaria» (Elias, 1982a: 43). 
¿Qué entiende Elias por discurso historiográfico? Me atrevo a proponer la siguiente formulación sintética que recoge consideraciones dispersas en sus textos y delimita el objeto de sus consideraciones críticas. Para Elias, el discurso historiográfico es un relato lineal que describe una sucesión de singularidades en el transcurso de un intervalo de corta duración y cuya verdad se fundamenta exclusivamente en la fidelidad a las fuentes documentales. La crítica eliasiana se centra en cada uno de los elementos contenidos en esa definición.

El punto de partida radica en mostrar las insuficiencias de una historia reconstruida a partir de relatos descriptivos y lineales. Un relato descriptivo es aquel que se limita a dar cuenta de lo sucedido, pretendiendo que el simple contar hace ya inteligible el acontecer histórico. Elias aduce, en contra, que la historia contada no es ya una historia inteligible porque todavía no ha sido explicada ${ }^{6}$. Un relato lineal es aquel que se desarrollo exclusivamente sobre la trayectoria de desarrollo temporal de algún objeto historiográfico, encerrándolo en sí mismo y dejando de lado sus conexiones con el desarrollo de otros objetos semejantes o diferentes. De este modo, se hace imposible la comparación, lo que bloquea en gran medida su inteligibilidad. La historia - y la sociología - han de ser, por el contrario, disciplinas comparadas, y el método de la comparación que Elias denomina intensiva debería ser su principio de vertebración? ${ }^{7}$.

La narrativa historiográfica que describe linealmente tiene un objeto típico o privilegiado: las singularidades históricas, ya sean presentadas en forma de acontecimientos o individualidades. Es una historiografía que sólo atiende a lo único e irrepetible, considerando ingenuamente que está inscrito en las características intrínsecas del acontecer histórico ${ }^{8}$. La crítica obsesiva de Elias a esta insuficiencia historiográfica es polifacética y domina sus escritos. Cuatro son los argumentos fundamentales. El primero desvela las fuentes ideológicas de tal prejuicio: la historia de los individuos es hija de una sociedad individualista; el historiador no hace más que proyectar anacrónicamente sobre el pasado sus prejuicios civilizatorios individualistas? ${ }^{9}$. Una segunda consideración crítica des-

${ }^{6}$ Esta crítica recurrente reaparece en uno de sus escritos más tardíos para destacar las insuficiencias de los nuevos historiadores de las mentalidades, en concreto Ariès: «este autor —asegura Elias - sigue entendiendo la historia como pura descripción. Va alineando las imágenes unas tras otras y muestra a grandes rasgos el cambio de forma experimentado. Lo cual es interesante y estupendo. Pero no explica nada» (Elias, 1987a: 20).

La reivindicación de la comparación no debe, según Elías, llevar a los defectos del comparatismo extensivo de Weber, sino desarrollarse a partir del estudio intensivo de un caso, complementado por su comparación con otros casos semejantes y diferentes (Elias, 1982a: 36). Su modelo sería el tipo de investigación desarrollado en La sociedad cortesana.

${ }^{8}$ El privilegio de la singularidad va de la mano de la ingenuidad positivista que dicta que así la historia se muestra a sí misma: «La idea según la cual la unicidad e irrepetibilidad de los acontecimientos son una nota característica y distintiva de la historia humana, del objeto de la investigación histórica, va ordinariamente acompañada de otra idea, a tenor de la cual esta "irrepetibilidad" está fundamentada en la naturaleza del objeto, esto es, en la realidad misma, independientemente de todas las valoraciones de los investigadores» (Elias, 1982a: 20).

9 Este énfasis en la individualidad, advierte Elias, se limita a reflejar ahistóricamente «una 
vela que nada puede ser en sí mismo singular o genérico, sino sólo en razón del principio de descripción en que se sustenta: lo que desde una perspectiva es singular, desde otra puede ser genérico ${ }^{10}$. Un tercer argumento destaca que lo singular o episódico no es sino el aspecto más llamativo y ruidoso de la historia, producto en realidad de corrientes menos visibles y llamativas que deberían ser el centro de atención del historiador ${ }^{11}$. Un cuarto y decisivo argumento muestra el carácter teóricamente subdesarrollado de toda historiografía que enfatice aisladamente las singularidades, ya que éstas sólo son posibles e inteligibles en el marco de las figuraciones sociales en las que están inscritas ${ }^{12}$.

Otro aspecto de la historiografía destacado críticamente por Elias es su tendencia a tomar en consideración intervalos temporales de corta o limitada duración, utilizando con frecuencia el intervalo duracional de una vida individual como marco idóneo para el relato ${ }^{13}$. Al proceder así, la historiografía segrega el proceso histórico de otros dos procesos fundamentales con los que debería conectarse: los procesos evolutivos y de desarrollo social ${ }^{14}$. Especial-

forma social específica de la autoconciencia humana» (Elias, 1982a: 21) surgida en lo que denomina la sociedad de los individuos (Elias, 1990a).

${ }^{10}$ No hay singularidades categóricas y con independencia de la plataforma de descripción. En realidad, "hay unicidades e irrepetibilidades de diverso grado y lo que en el ámbito de un grado es único e irrepetible puede, visto desde otro grado, parecer repetición y eterno retorno de lo mismo" (Elias, 1982a: 21).

${ }^{11}$ Los cambios sociales fundamentales, subraya Elias, «ocurren muy despacio a lo largo de un período considerable, paso a paso y en gran medida sin ruido a oídos de los que sólo son capaces de escuchar los grandes acontecimientos. Las explosiones en las que la existencia y las actitudes de las gentes resultan cambiadas de forma abrupta y, por ello, de forma especialmente perceptible, no son más que acontecimientos particulares en el marco de esos cambios sociales lentos y casi imperceptibles, cuyos efectos sólo se pueden captar si se comparan diferentes generaciones» (Elias, 1982c: 265). La historia de los acontecimientos es, pues, una historia de fuegos fatuos.

${ }_{12}$ Este argumento es clave para la reconducción sociológica de la historia y es la espina dorsal del análisis de Luis XIV en La sociedad cortesana o de Mozart en la obra del mismo título. Elias no propone una reducción sociológica de las individualidades históricas, sino una aproximación que contemple al individuo en el seno de su figuración histórica como marco que delimita posibilidades de autonomía que aquél puede explotar en mayor o menor medida en razón de sus peculiaridades personales. Sólo así, advierte al tratar el caso de Mozart, "se puede comprender qué presiones inevitables se ejercían sobre una persona y cómo se comportaba ésta con respecto a estas presiones; si se doblegaba ante ellas, y por tanto también en su creación musical quedaba marcado por ellas, o si intentaba escapar o tal vez incluso resistirse a ellas» (Elias, 1991b: 25).

${ }^{13}$ En The Symbol Theory expone por extenso este argumento: "para que una aproximación sociológico-procesual sea fructífera [...] tiene que distanciarse de la aproximación propiamente histórica. Esta última está básicamente centrada en procesos sociológicos de corta duración. En términos históricos un siglo puede ser una larga distancia temporal; en términos de la sociología de los procesos puede reconocerse como un lapso temporal de corta duración. Con frecuencia, los historiadores sólo son capaces de utilizar el lapso temporal de la vida de un individuo como vara de medir los cambios en otros niveles sociales [...] Y en tal caso muchas conexiones de un proceso en marcha [...] pueden quedar sin percibir e invisibles» (Elias, 1991a: 16).

${ }^{14} \mathrm{Y}$ así afirma tajantemente que "la discusión de los problemas básicos entre sociología e historia se ha visto dificultada por el hecho hasta ahora normal de que [...] no se ha elaborado clara y distintamente la diferencia y la relación entre evolución biológica, desarrollo social e historia 
mente significativo es este último, ya que en él se encuentra la clave para comprender las transformaciones históricas. En consecuencia, una historiografía condenada a la miopía temporal del tiempo corto está abocada a permanecer en la superficie de lo histórico, dejando de lado los fundamentales cambios sociales ocurridos.

El aparato crítico de Elias se centra también en las insuficiencias de lo que la historiografía ha presentado como fundamento de la veracidad de los relatos: el estudio crítico de las fuentes documentales. Las objeciones que presenta destacan la desproporción e incongruencia entre la limitada información proporcionada por las fuentes y el resultado final al que el historiador llega o debería llegar. Resultado a que el historiador llega porque éste presenta típicamente un relato continuado y selectivo a partir de fuentes heterogéneas y fragmentarias, guiándose por criterios que se atienen a sus valores e ideales y que, consecuentemente, no pueden sustentar la pretensión rankeana de la objetividad imparcial del relato ${ }^{15}$. Resultado al que debería llegar porque si la historiografía hiciera inteligible el acontecer pasado habría de apoyarse no sólo ni principalmente en las huellas documentales o monumentales del pasado, sino también en los modelos o hipótesis explícitos que hacen posible acceder a tal inteligibilidad $^{16}$.

Como se ha podido comprobar, la crítica de Elias es suficientemente sistemática y coherente. Enfrenta las múltiples pretensiones de la historiografía y da cuenta de sus fundamentales saberes tácitos. Lo que habría que ver es si esa crítica es justa y constituye un punto seguro de partida para fundamentar una alternativa viable.

Como hombre situado entre dos mundos, en cierta medida Elias permanece en, y reproduce, el universo del que se quiere distanciar críticamente. Como algún historiador inclemente ha destacado, la sociología histórica de Elias es, en una parte no desdeñable, continuación del programa denostado de Ranke y reproduce sus insuficiencias ${ }^{17}$. Pero ésta no puede ser la objeción fundamental

[... que] constituyen tres etapas, diversas pero inseparables, de un proceso que engloba a toda la humanidad, cada una de las cuales tiene un ritmo de transformación distinto" (Elias, 1982a: 2324). En razón de esto, los estudios históricos deberían desarrollarse a la luz de los problemas de desarrollo social a largo plazo, pues sólo en ese marco se hacen significativos.

15 De este modo, la historia se ve abocada a la paráfrasis continua, pues «cada generación elige ciertas ruinas del pasado y las dispone, según sus propios ideales y valoraciones, para construir sus viviendas características» (Elias, 1982a: 16).

${ }^{16}$ La objeción de Elias se construye en contra de la ingenua pretensión según la cual las fuentes hablan por sí mismas y el historiador es un simple traductor de sus dictados: "En tanto que las referencias a las fuentes son verificables, la combinación e interpretación de los fragmentos queda en gran medida al arbitrio del investigador individual. A éste le falta el firme apoyo que en ciencias más maduras dan al estudioso individual los modelos de relación —llamados hipótesis y teorías - cuyo desarrollo está vinculado en ellas con el conocimiento de datos concretos, mediante un constante reacoplamiento (Elias, 1982a: 15-16).

17 El historiador Barraclough (1983: 120) ha destacado con razón que el anti-rankeano Elias es muy rankeano en el desarrollo concreto de su sociología histórica: "Elias sigue anclado en la tradición rankeana y centra toda su atención en cortes y gabinetes; como la de Ranke (pero con 
en contra de la empresa crítica de Elias. La objeción fundamental es que en gran parte se limita, tal vez sin saberlo, a rematar un cadáver ya bien muerto y hasta enterrado cuando él escribe ${ }^{18}$. Y, en efecto, el ingente aparato crítico eliasiano da de lleno en las insuficiencias de la historiografía episódica decimonónica, pero carece de relevancia para gran parte de la historiografía del siglo XX. Es más, uno puede encontrar punto por punto las críticas eliasianas en representantes de escuelas historiográficas anteriores o contemporáneas de sus escritos críticos y, lo que es más importante, la puesta en marcha de ingentes investigaciones historiográficas que desconfían del relato, exigen una historia inteligible, huyen de la linealidad, se mofan del acontecimiento, apuestan por el tiempo largo y renuevan la consideración y el peso acordado a las fuentes documentales ${ }^{19}$.

La crítica de Elias está, pues, desfasada; todo lo más, resume lo que los historiadores principales de nuestro siglo se han cansado de repetir en contra de la historiografía del siglo anterior. Es, por lo tanto, injusta al pretender dirigirse contra la historiografía en general y, consecuentemente, no puede afrontar ni resolver el problema prioritario que la mueve: el problema de la convergencia entre la historia y la sociología.

El anterior juicio puede parecer, a su vez, injusto, producto de un abuso que Elias temía, "la arrogancia retrospectiva de los que vivimos en una época posterior»(Elias, 1991b: 34). No quisiera caer en la victoria pírrica que esa arrogancia asegura, pero es indudable que a la hora de enjuiciar a nuestros clásicos los debemos pensar desde hoy, es decir, desde los problemas que nos parecen decisivos y las soluciones que nos afanamos en encontrar. Lo que hemos de preguntarnos es si los percibieron y las esbozaron. Mi impresión es que, en este caso, Elias es tan sólo un muy primerizo Juan Bautista: avisa sobre algo, lo entrevé, pero no lo indica claramente porque está demasiado pendiente del pasado.

Argumentaré la posición que me lleva a adelantar ese juicio. Como he propuesto en Ramos (1993), el problema de la integración o convergencia de la sociología y la historia sólo se puede abordar si se toma en consideración la paradoja constitutiva del proyecto de la sociología histórica, es decir, esa relación de atracción y repulsión existente entre sus tres elementos típicos: la narración, la comparación y el análisis. Para abordar esto, de poca ayuda son las consideraciones críticas de Elias sobre la historiografía.

$\mathrm{Y}$ son de poca ayuda porque sufren insuficiencias fundamentales. Parten de

menos excusas), su concepción de la historia es explícitamente eurocéntrica; como Ranke, considera al Estado el eje de la actividad humana.»

${ }_{18}$ En este sentido, Kocka, en el artículo publicado en este número, destaca acertadamente que la crítica de Elias «estaba incluso un poco anticuada cuando se dio a conocer en Alemania alrededor de 1969».

19 Es evidente que basta con considerar a Braudel (1980) y los historiadores de los Annales (cfr. Le Goff y Nora, 1978-1980) para encontrar punto por punto las críticas a esa historiografía tradicional episódica que Elias arbitrariamente identifica con la historiografía sin más. 
un desdén en contra de la narración como estrategia discursiva y así son incapaces de prever los problemas que toda historiografía programáticamente antinarrativista ha de generar, sobre todo desde la óptica de una sociología que, como la de Elias, enfatiza el carácter procesual de la realidad social. En efecto, una historiografía antinarrativista está abocada a una doble deficiencia: por un lado, está abocada a ser infiel a sí misma y no cumplir cabalmente su programa ${ }^{20}$; por otro lado, se ve arrastrada a sumarse a la ofensiva antitemporalista, convirtiendo el rechazo del acontecimiento en la apoteosis de esa atemporalidad característica de las estructuras dormidas y silenciosas de las que habla Braudel ${ }^{21}$. En cualquiera de los casos, se habría de convertir en una historiografía deficiente desde la perspectiva de quien, como Elias, reivindica lo histórico-procesual.

Las indicaciones de Elias son también deficientes porque conciben de forma muy ingenua el momento analítico propio de la sociología histórica y aproblemáticas las relaciones entre análisis y comparación. En efecto, las reflexiones epistemológicas de Elias adolecen de un ingenuo positivismo cuya mayor originalidad consiste en haber pasado por el diván psicoanalítico ${ }^{22}$. En razón de ello, y de una forma insistente a lo largo de su obra, se apuesta por el distanciamiento afectivo como garantía segura de un saber científico irreprochable. Bastará con que los científicos sociales se distancien de sus temores e ideales valorativos y no los proyecten sobre el material que están estudiando, para que automáticamente las hipótesis interpretativas se amolden adecuadamente a la historia real y ésta deje de ser incansablemente parafraseada ${ }^{23}$.

${ }^{20}$ No lo cumple cabalmente porque no puede hacer lo que pretende: prescindir de la narración para dar cuenta del acontecer histórico. En este sentido, Ricoeur (1983: 287 ss.) ha demostrado, tras una atenta lectura de la historiografía de Braudel, que en su obra no se prescinde ni del acontecimiento ni de la narración, como programáticamente se proclama. Y ello es así porque sin narración no se puede dar cuenta de la temporalidad del acontecer. Evidentemente, esto no convierte a la historia en pura narración; se limita a mostrar que es uno de sus elementos fundamentales.

${ }^{21}$ Como, entre otros, destaca Stone (1986: 100-101), la tendencia de esa «nueva» historiografía a centrar su atención en las estructuras la lleva a deslizarse hacia una histoire immobile en la que se volatiliza la realidad como proceso de cambio.

${ }^{22}$ Es clara la impronta positivista en la epistemología de Elias: conocimiento científico es aquel que se atiene metódicamente a un conjunto de hechos circunscritos y los lee a partir de marcos teóricos adecuados. De ahí su elogio explícito de Comte (Elias, 1982b: 37 ss.). Pero también es cierto que la pureza epistemológica está mediada por un correlato de psicoanálisis que se explicita en la teoría de distanciamiento: la objetividad científica se logra gracias al distanciamiento afectivo o emocional en relación al objeto que se observa, de modo que no interfieran los impulsos libidinales — cfr., en este sentido, Elias (1990b: 11 ss.), Featherstone (1987), Béjar (1991) y notas 61, 62 y 63-. De ahí la imagen del sociólogo como «cazador de mitos» (Elias, 1982b: 62); mitos que son tanto los «idola» baconianos-comtianos como las "fantasías neuróticas» freudianas. Consecuentemente, Elias desvela así en qué consiste «el secreto de la ciencia: renunciando a las ilusiones, a las fantasías o, dado el caso, también al temor y a la angustia, desarrollar de tal manera los conocimientos del mundo que se adapten con la mayor exactitud al mundo real [... o permitan] ver el mundo tal como es» (Elias, 1988: 18, 12).

${ }^{23}$ En este sentido, el argumento constante de Elias para dar cuenta del subdesarrollo científi- 
¿Qué ocurre con la comparación? Elias se limita a reivindicar la necesidad de proceder a comparar tanto en el campo histórico como en el sociológico, pero, más allá de la crítica al comparatismo extensivo y formalista de Weber (Elias, 1982a: 36), pocas indicaciones brinda sobre la lógica y los límites del método comparado y sus tensas relaciones con la teoría. No se trata de un problema que aborde y desbroce y, por ello, poco podemos esperar de sus escritos.

En definitiva, el resultado que alcanzamos tras esta primera aproximación al problema eliasiano de la historia nos indica ya algunas de sus glorias y miserias. Elias subrayó la relevancia sociológica del conocimiento histórico y construyó una sistemática argumentación crítica en contra de una historiografía (tradicional) insensible a las aportaciones de la sociología. Pero no prestó atención a la nueva historiografía que, en parte, le era anterior y, desde luego, contemporánea. En razón de ello no atisbó los problemas que, más allá de su forma discursiva tradicional, comporta el conocimiento histórico en esa tarea de aproximación al conocimiento sociológico cuya conclusión es la empresa en la que estaba trabajando: la sociología histórica.

Como se indicó anteriormente, la empresa crítica de Elias fue bifronte: su rechazo de la historiografía fue siempre de la mano del rechazo de la sociología hegemónica $^{24}$. Si a aquélla le objetó su indiferencia hacia la sociología, a ésta le criticó vivir de espaldas a la historia. Reconstruida sistemáticamente, esta última crítica se desarrolla en dos planos escalonados: en el primero se rechaza su ahistoricismo temático; en el segundo, su ahistoricismo sustantivo ${ }^{25}$. Entiendo por ahistoricismo temático la ausencia de indagaciones sociológicas sobre hechos, procesos o épocas históricas, lo que se materializa en una atención unilateral a la actualidad inmediata y a una falta de interés por, o un inadecuado tratamiento de, los problemas generales del desarrollo histórico. Entiendo por ahistoricismo sustantivo la ausencia de un aparato conceptual apropiado para el estudio de lo histórico en el que se prime metodológicamente la diacronía, el devenir y el carácter procesual de la realidad social. Estas dos decisivas

co de las ciencias sociales en relación a las ciencias «duras» consiste en destacar el «retraso» o las dificultades que aquéllas sufren en el proceso de distanciamiento o descentramiento afectivo (cfr. Elias, 1982b: cap. 2. ${ }^{\circ}$; 1978: 252 ss., sobre la crisis del geocentrismo en física y el retraso de su equivalente funcional en las ciencias sociales).

${ }^{24}$ En sus dispersas consideraciones críticas, Elias suele enfrentarse con lo que denomina sociología dominante. Cuando las críticas se particularizan o especifican más, se presenta a Parsons y el funcionalismo como sus representantes característicos (cfr. Elias, 1978: 225 ss.).

${ }_{25}$ Tal como utilizo el concepto, ahistoricismo nada tiene que ver con la polémica clásica sobre el historicismo y sus posibles miserias. Hace referencia tan sólo a la ausencia de la historia en el seno de la sociología. La diferencia entre ahistoricismo temático y sustantivo se inspira en la propuesta de Martins (1992: 188 ss.), que, estudiando la recepción del problema del tiempo en la ciencia social contemporánea, distingue entre el temporalismo temático y el sustantivo. 
ausencias de la historia constituyen, tal como interpreto la posición de Elias, las fundamentales deficiencias de la sociología de nuestra época.

En ese primer plano crítico, Elias rechaza la idea de que la sociología se pueda construir adecuadamente atendiendo exclusivamente a la actualidad contemporánea. Esa "retirada del sociólogo en el presente» y su concomitante "fuga del pasado" (Elias, 1987b: 223) no pueden sino bloquear el desarrollo del conocimiento sociológico. Las razones son múltiples. Por un lado, Elias asegura que "quien permanece absorto en las cuestiones de actualidad sin mirar más allá de ellas puede considerarse prácticamente ciego» (Elias, 1988: 7). Implícitamente, para él la historia sigue siendo magistra vitae y, por lo tanto, su estudio nos sigue brindando enseñanzas relevantes cara al presente a pesar de las diferencias que nos separan de otras épocas. Pero, más allá de esto, sus dos argumentos críticos fundamentales son, por un lado, que la historia constituye un imprescindible laboratorio para la comparación sociológica y, por el otro, que cualquier momento histórico, ya sea actual o pretérito, sólo es inteligible en el marco de la dinámica de que ha surgido y en la que se aden$\operatorname{tra}^{26}$. Hay, pues, que reorientar temáticamente la sociología hacia el estudio de la historia incluso en el caso de que nuestra preocupación dominante sea la comprensión del presente inmediato en el que estamos instalados.

La tematización de la historia es también imprescindible porque la sociología tiene como uno de sus cometidos más urgentes el estudio del desarrollo social $^{27}$. Elias asegura que la sociología hegemónica o ha vuelto sus espaldas al problema del desarrollo social o lo ha analizado inadecuadamente. Ha vuelto sus espaldas porque la vieja cuestión «de cómo pasan las sociedades en su desarrollo de una fase a otra ha desaparecido del círculo de intereses de los teóricos más destacados de la sociología» (Elias, 1982b: 184) ${ }^{28}$. Cuando lo ha abordado,

26 Según resalta Elias, la unilateral actualización de la sociología nos impide recurrir al laboratorio histórico-comparado cuando, en realidad, "las condiciones del presente se pueden ver con mayor claridad si se comparan con las condiciones del pasado"; por otro lado, "el ámbito de la explicación se estrecha indebidamente si la investigación se centra en los problemas contemporáneos. No se puede ignorar el hecho de que cada sociedad presente ha surgido de sociedades anteriores y apunta más allá de sí misma hacia futuros posibles» (Elias, 1987b: 235, 226).

${ }_{27}$ Cfr. nota 14. Las transformaciones sufridas por la humanidad han de conceptuarse doblemente: por un lado, como evolución biológica; por el otro, como desarrollo social. Ambos procesos «están centrados en la transmisión de los medios de supervivencia de generación en generación y en sus cambios [...] Pero lo que se transmite y cómo se transmite difiere seriamente en los dos casos. En el caso de la evolución, el principal instrumento de transmisión y cambio es una estructura orgánica denominada "gen". En el caso del desarrollo, el instrumento principal de transmisión y cambio son los símbolos en el sentido más amplio de la palabra que incluye no sólo el conocimiento, sino también, por ejemplo, modelos de conducta y sentimiento» (Elias, 1991a: 23). Hay que limitar, pues, la utilización del término evolución para los procesos de transformación mediados genéticamente y utilizar el término desarrollo para las transformaciones sociales mediadas simbólicamente. Las primeras definen un proceso irreversible; las segundas, un proceso potencialmente reversible (Elias, 1991a: 33; 1982a: 24).

${ }^{28}$ Esta crítica es el centro temático de la Introducción (publicada en 1968) a la 2.a edición de El proceso de la civilización (Elias, 1978: 221-263) y de muchas de las páginas de Sociología 
lo ha analizado inadecuadamente porque ha centrado unilateralmente su atención en alguno de sus aspectos (los económicos), sin aunar la doble perspectiva intra y extrasocietal y desatendiendo el problema estratégico del poder (Elias, 1982b: 204-214).

La otra cara de la crítica eliasiana a la sociología hegemónica consiste en el rechazo de su ahistoricismo sustantivo, proponiendo como alternativa una historización sistemática del aparato teórico y el lenguaje $\mathrm{e}^{29}$ sociológicos que vertebre una sociología figuracional. Se trata del aspecto más interesante del programa de "reforma sociológica» de Elias y precisa un estudio cuidadoso.

Entiendo por historización del aparato teórico de la sociología su transformación en términos que sean apropiados para que dé cuenta de —es decir, describa y eventualmente haga inteligible — su objeto característico: la realidad histórico-social, entendida como campo de relaciones y procesos ${ }^{30}$. Tal transformación — que ha de afectar a la metodología, la teoría y el léxico de la sociología - se fundamenta en términos ontológicos. Es la ontología de lo social, como ontología de lo histórico, la que exige una transformación así.

Para proponer una tal línea interpretativa sobre las propuestas teóricas estratégicas de Elias me apoyo en: a) sus reiteradas críticas a las tres caras del sustancialismo sociológico, es decir, su estatismo, finitismo y dualismo; $b$ ) su reivindicación de una realidad sociohistórica procesual, y c) sus propuestas a favor de una sociología figuracional que sea capaz de superar los límites criticados en $a$ ) y dé cuenta de la realidad reivindicada en $b$ ).

La crítica al sustancialismo sociológico arranca de la refutación del estatismo. Se muestra cuando Elias rechaza el doble legado de Parsons: su analítica universal y su sistemismo homoestático. A su entender, la analítica de las variables-pauta se limita a una combinatoria de conceptos atemporales que reduce, y no puede dar razón de, la riqueza de la evidencia histórica. Por su parte, el sistemismo homoestático tiene el defecto de concebir las distintas sociedades como totalidades estáticas congeladas en un equilibrio funcional para el que el cambio

fundamental (Elias, 1982b: 175-185, 193-214). Elias argumenta que una cosa es criticar la caracterización inadecuada del desarrollo social que proporcionaron las teorías evolucionistas del XIX y otra muy diferente prescindir del concepto mismo de desarrollo. Parsons y la sociología hegemónica han confundido ambas cosas, de forma que «las teorías de la evolución de la sociedad no [han] jugado papel alguno en la sociología del siglo XX» (Elias, 1982b: 183). Esta crítica eliasiana no deja de ser sorprendente y resultar extemporánea si se considera que aparece a los pocos años de la publicación de Societies. Evolutionary and Comparative Perspectives, de Parsons (1966), obra que habría de marcar el surgimiento del neoevolucionismo contemporáneo.

29 Son constantes en la obra de Elias los llamamientos en favor de una «reforma» del lenguaje (no sólo sociológico) que lo haga acorde con el dinamismo, procesualidad, interpenetración e interdependencia propios de la vida social cotidiana. Al tema dedica una sección de Sociología fundamental (Elias, 1982b: 132 ss.). Cfr. Bourdarias (1991).

${ }^{30}$ Elias no utiliza el concepto de «campo" para designar la realidad de la que la ciencia social ha de dar cuenta. Con todo, como ha destacado Bourdarias (1991: 254), la imagen de un campo fija bien la idea que propone críticamente el concepto de figuración: un objeto constituido por relaciones y procesos, no por sustancias temporalmente fijas y espacialmente circunscritas. 
social sólo puede ser una rareza o una excepción ${ }^{31}$. En ambos casos se presupone una ontología social estática, algo así como si el mundo sociohistórico fuera el sucederse de composiciones fijas de fotos de un mismo álbum atemporal.

Esta ontología estática va de la mano de un finitismo que presenta la realidad social como un conjunto de entes circunscritos, claramente delimitados, con estrictas fronteras que fijan dónde acaban unos y comienzan otros. Producto característico de ese finitismo es la degeneración de todos los problemas sociológicos en dualismos arbitrarios reconducibles, en última instancia, al estéril dilema Individuo/Sociedad ${ }^{32}$.

Frente a esta ontología social, Elias propone la alternativa de una ontología temporalista o procesual. Se trata de una alternativa cuyos fundamentos son cósmicos y antropológicos. Cósmicos porque, según asegura Elias, el universo material se presenta como un "conjunto de entidades sumidas en transformaciones desde tiempos inmemoriales» (Elias, 1990b: 159); antropológicos, porque también "el hombre es proceso" (Elias, 1982b: 142; énfasis N. E.). En razón de esto, la realidad social se nos muestra como un proceso que se desarrolla históricamente y para el que la ciencia social ha de proporcionar modelos adecuados que lo hagan inteligible. Enunciado en sus propios términos, sólo se aborda adecuadamente «la problemática de la sociología si no se hace abstracción de los movimientos, del carácter procesual, y si para la investigación de cualquier situación dada se utilizan como marco de referencia conceptos que den cuenta del carácter procesual de las sociedades y de sus diferentes aspectos» (Elias, 1982b: 139).

Aparece así la alternativa eliasiana a la sociología hegemónica. Una alternativa que en algún texto es denominada sociología "evolutiva» (Elias, $1982 b$ : 185), pero las más de las veces recibe la etiqueta de «figuracional», «procesual» o "procesual-figuracional ${ }^{33}$. Su llave maestra es el concepto de fi-

${ }^{31}$ Esta revisión crítica de la analítica y la sistémica de Parsons aparece ampliamente desarrollada en la introducción a la 2. a edición de El proceso de civilización (Elias, 1978: 225 ss.), donde Elias subraya la distancia entre su aproximación, que enfatiza el carácter procesual de la realidad social y el cambio histórico, y la aproximación parsoniana. Se trata de uno de los pocos textos relativamente extensos en el que Elias aborda directamente la crítica de propuestas teóricas de otros autores con nombres y apellidos.

${ }^{32}$ La representación paradigmática de ese finitismo es el homo clausus, al que, en distintas ocasiones, dedica Elias su aparato crítico. La contraparte del homo clausus es una sociedad pensada como sistema por encima de los actores. Ambos son entes cerrados sobre sí mismos. En razón de ello, del finitismo se desemboca en el dualismo, que tanto ha empantanado el desarrollo de la sociología (cfr. Elias, 1978: 245 ss.; 1982a: 190 ss.; 1982b: 141 ss.).

${ }_{33}$ El énfasis en las figuraciones es más característico de sus primeras obras fundamentales: $E l$ proceso... (1978, 1982c), La sociedad cortesana (1982a), Sociología fundamental (1982b), mientras que en trabajos posteriores como La sociedad de los individuos (1990a) o, por ejemplo, en su libro póstumo, The Symbol Theory, habla de process-sociological approach (Elias, 1991a: 16). A mi entender, no hay un cambio sustantivo en esa variación, ya que la figuración no es sino el concepto sociológico que intenta dar cuenta de los procesos. Sobre las relaciones entre la sociología figuracional de Elias y la sociología formal de Simmel (una relación que merecería una investigación cuidadosa), cfr. las apreciaciones de Bauman (1979). 
guración ${ }^{34}$ que aquí y allá presenta Elias como el bálsamo que ha de aliviar los males sociológicos. La semántica de este concepto no está todo lo clara que su decisivo protagonismo demanda; se hace patente más por sus connotaciones críticas y sus variadas ilustraciones metafóricas que gracias a una explícita y sistemática acotación ${ }^{35}$. Con todo, utilizando las múltiples aproximaciones puntuales de Elias, cabe proponer la siguiente definición: una figuración es un entramado dinámico de interdependencias sociales ${ }^{36}$.

La utilización de un concepto así supondría, según Elias, la obsolescencia radical del aparato categorial básico de la sociología. Se podría prescindir de sus conceptos claves, como los de «sistema", "acción», "relación social», «interacción social», "poder» —o por lo menos redefinirlos radicalmente- (Elias, 1982b: 190-196). Y, prescindiendo de ellos, se lograría erradicar el sustancialismo y la vieja ontología estática, finitista y dualista. En efecto, el énfasis figuracional en el dinamismo permitiría conseguir la superación del estatismo; el énfasis en su carácter de entramado, superar el finitismo; y el dualismo, por su parte, sería erradicado gracias al concepto de interdependencia. Con ellos desaparecería el sustancialismo sociológico, sustituido por la idea de una realidad social concebida como campo de relaciones y procesos.

Más adelante (en el siguiente parágrafo) se analizará cumplidamente el

34 Figuration es un término que en alemán forma parte del lenguaje musical, definiéndose como «adorno de una figura o una melodía». En las, a veces pésimas, traducciones castellanas de la obra de Elias ha sido traducido preferentemente como "figuración" o "configuración» y, en algún caso (El proceso de la civilización), como "composición». Aunque sea ésta la traducción más próxima al sentido eliasiano, utilizaré la que está más extendida, es decir, el término "figuración». Es evidente que su significado en este contexto no incorpora sus acepciones características en castellano: «acción de figurarse algo», "cosa que uno se imagina», «fantasía».

${ }^{35}$ Béjar $(1991: 69,80)$ destaca con razón que la noción de figuración sólo queda «esbozada» en la obra de Elias y, al final, resulta que "promete más que cumple». Explícitamente, Elias confiesa que ha introducido el término para "flexibilizar» las presiones lingüísticas dualistas (individuo vs sociedad) (Elias, 1982b: 156), adelantando que es una palabra "menos cargada de connotaciones» que se propone en sustitución del concepto de sistema y su característica hipóstasis de lo social (Elias, 1982a: 31). Pero a la hora de aclarar positivamente el concepto tiende a refugiarse en la metáfora de la danza (Elias, 1978: 262), en los "modelos pedagógicos» de los juegos (Elias, 1982b: 108) o en una simple representación gráfica que recibe comentarios muy someros (ibid.: 15-16). Es como si la simple introducción de un término nuevo y sustitutorio, básicamente especificado en términos de metáforas, fuera ya una rigurosa construcción conceptual. ¡Resulta curioso que el «distanciado» Elias creyera en el poder mágico de las palabras!

${ }^{36}$ En los múltiples contextos de uso en que Elias especifica el concepto de figuración, aparece típicamente: a) el énfasis en la estructura, entendida como el entramado o urdimbre que pone en relación a los individuos [«he venido utilizando el término "figuración” como término general para designar la estructura formada por personas interdependientes» (Elias, 1990b: 112$113)$ ]; b) el énfasis en su dinamismo interno o procesualidad [«las personas, en tanto individuos o grupos, están relacionadas mutuamente en figuraciones específicas cuya dinámica ejerce una influencia a menudo irresistible y coercitiva sobre aquellos que forman la figuración (ibid.: 105)]; c) el énfasis en la interdependencia [«con el concepto de figuración se sitúa [...] el problema de las interdependencias humanas en el centro del planteamiento teorético de la sociología» (Elias, 1982b: 161)]. El análisis más sistemático del concepto de figuración aparece en Sociología fundamental (Elias, 1982b: 154-160). 
dinamismo propio de las figuraciones (o de sus mecanismos), ya que ese aspecto es fundamental en la resolución eliasiana del problema de la historicidad. Me centraré aquí en los otros dos aspectos, enfatizando el último, que, por los motivos que se aducirán, parece el más decisivo.

El carácter de entramado de las figuraciones es el argumento básico del que se sirve Elias para romper con lo que anteriormente he denominado finitismo. Frente a un mundo de entes claramente circunscritos, los entramados figuracionales muestran el carácter fundacional y ontológicamente privilegiado del concepto de relación. Lo relevante no son los entes en sí mismos, sino la relación que los une, la cual, al interpenetrarlos, desborda o supera las fronteras que supuestamente los delimitan. En razón de esto, sus límites se convierten en borrosos, siendo imposible, por lo menos desde la perspectiva de distanciamiento en la que se sitúa la sociología, decidir de forma tajante qué es lo propio de, o lo interior a, cada uno de ellos ${ }^{37}$. Ocurre así con el concepto general de individuo y, de forma aún más clara, con esos individuos especialmente poderosos que fueron los autócratas absolutistas. No es sensato indagar en casos así qué es lo que de individual tenían y qué de reflejo de la situación social en que vivían porque no se trata de un universo de entes finitos rodeados de fronteras potentes y con estrictos aduaneros. Luis XIV vivía en un entramado en el que era a la vez el todo y la parte. Disolver esta paradoja es también negarse a comprenderlo histórico-sociológicamente; es apostar por un finitismo esterilizante ${ }^{38}$.

La relevancia ontológica del concepto de entramado figuracional no resulta, pues, desdeñable. La lógica de sus implicaciones nos conecta con su otro aspecto característico: la interdependencia. Anteriormente se ha anunciado que éste es el aspecto más relevante de las figuraciones: constituir un entramado de interdependencias. Este juicio lo abonan propuestas teórico-sustantivas de Elias. Me refiero a sus propuestas sobre lo que denomina «la triada de controles básicos» que se cuentan entre «los universales de la sociedad»: control del

${ }^{37}$ Estas propuestas informan los análisis eliasianos sobre los juegos (Elias, 1982b: 85 ss.), la serie de los pronombres personales (ibid.: 147 ss.) y el homo apertus (ibid.: 140 ss.) como casos de entramado figuracional. La hipótesis fundamental es que los conceptos sociológicos han de ser elaborados como "conceptos de relación» (ibid.: 92) y que, consecuentemente, "es más apropiado pensar lo relacionado a partir de las relaciones» (ibid.: 139), es decir, como entes interpenetrados cuyos límites resultan borrosos. Por otro lado, concebir las realidades como relaciones de interpenetración es ya reconocerlas como procesos, pues «toda relación entre personas es un proceso" (ibid.: 93). De este modo, el relacionismo sociológico se hermana con el procesualismo temporalista.

${ }_{38}$ Sobre este tema se insiste mucho en La sociedad cortesana: "No se puede plantear el problema como si la individualidad de Luis XIV se hubiese desenvuelto independientemente de las posiciones sociales que ocupó primero como heredero al trono y después como rey; ni tampoco como si el desarrollo de estas posiciones sociales fuera completamente autónomo respecto del de su detentador» (Elias, 1982a: 39). Además, la propuesta se generaliza: «la grandeza de un hombre sólo puede entenderse propiamente si se consideran las imbricaciones y vínculos a partir de los cuales y en los cuales éste piensa y actúa» (ibid.: 226). El tema vuelve a ser abordado en Mozart. Sociología de un genio (cfr. Elias, 1991b: 24-25). 
entorno extrahumano, control de las conexiones sociales y autocontrol humano (Elias, 1982b: 189-190). El desarrollo social no sería sino la sucesión de las respuestas sociofiguracionales que se han dado a esos tres problemas universales. De aquí que el estudio de la interdependencia sea decisivo.

Hablo de interdependencia porque en este sentido es reconstruible la posición de Elias en relación a lo que en el lenguaje sociológico usual se denomina poder o control. Elias utilizó también estos términos, pero siempre advirtiendo que los utilizaba de una manera tal que encontraba su mejor traducción en el concepto de interdependencia o coacción recíproca ${ }^{39}$.

¿Qué entendía por tal y cómo cualificaba conceptos más usuales como poder o control? En algunos textos privilegiados lo explicita, proponiendo que en cuanto interdependencia el poder ha de ser concebido como una relación social caracterizada por ser multipolar, parcialmente recíproca y ambivalente o ambigua. Que el poder sea una relación es un tópico que Elias reitera para romper con ese juego del lenguaje que pretende que alguien "lo» puede tener y que, consecuentemente, es un bien al lado de muchos otros ${ }^{40}$. Que el poder sea multipolar significa que no se pueden reducir sus múltiples manifestaciones a una relación de relaciones en la que todas se subsuman ${ }^{41}$. Que el poder esté dotado de una cierta reciprocidad y que, por lo tanto, pueda ser una relación asimétrica y simétrica a la vez significa, por un lado, que es una relación describible en un continuo (que va de un más a un menos) no sometido a la lógica del juego de suma cero y, sobre todo, que dominadores y dominados tienen poder recíproco los unos sobre los otros, aunque en distinta medida ${ }^{42}$. Por últi-

39 La razón que alega Elias en distintos contextos críticos es que el concepto de poder está demasiado identificado en el lenguaje común, pero también en el lenguaje técnico, con la idea de una relación unívoca, exclusivamente asimétrica y coherente. La alternativa que contrapone (multipolaridad, simetría relativa y ambigüedad del poder) le lleva a proponer que se prescinda de ese concepto: «En toda forma de "poder" [...] se trata de relaciones de equilibrio más o menos lábiles y sobre todo de equilibrios de poder. Como instrumento analítico más global hay que preferir el concepto de "coacción", entendiéndolo en el sentido de una coacción recíproca de hombre sobre hombres, aunque no necesariamente de la misma fuerza” (Elias, 1982a: 349).

${ }^{40}$ En las consideraciones sobre los juegos y los pre-juegos que se desarrollan en Sociología fundamental aparece esto como consideración central. El concepto de poder, subraya Elias, "ha de ser entendido como un concepto de relación» (Elias, 1982b: 91-92; énfasis N. E.), y nos dejamos engañar por el lenguaje cuando "decimos que un hombre tiene mucho poder, como si el poder fuera una cosa que uno pudiese llevar de aquí para allí en el bolsillo. Esta manera de hablar, en realidad, es un vestigio de ideas de carácter mágico-mítico. El poder no es un amuleto que uno posea y otro no; es una peculiaridad estructural de las relaciones humanas — de todas las relaciones humanas» (ibid.: 87; énfasis N. E.).

${ }^{41}$ A veces, Elias habla de la multipolaridad (1982a: 353) y otras del carácter polimórfico del poder o sus fuentes (Elias, 1982b: 109). En ambos se significa lo mismo: que las fuentes del poder son múltiples y no derivables entre sí y que en toda situación histórica hay múltiples relaciones de poder en las que se puede encontrar un mismo individuo, aunque esto no signifique que todas tengan el mismo peso. Bajo este prisma se desarrollan los análisis sobre la interdependencia en La sociedad cortesana (cfr. Elias, 1982a: caps. V y VI).

${ }^{42}$ Son varias las ideas que se entrelazan en esta propuesta. Por un lado, la idea principal de que en toda relación de poder se da un cierto equilibrio, cuyo exponente máximo sería la situa- 
mo, que el poder sea ambiguo o ambivalente significa que su característica relación se muestra típicamente en forma de esa paradoja pragmática denominada por Barel (1989: 223 ss.) estrategia doble: querer y no querer a la vez $\operatorname{algo}^{43}$.

Si la interdependencia redefine así las relaciones de poder y éstas son fundamentales tanto en términos lógicos (la triada de universales) como en términos históricos (desarrollo social como desarrollo de las hetero y autocoacciones), entonces se alcanza la conclusión de que las figuraciones, en cuanto entramados dinámicos de interdependencias, también erradican esa ontología dualista característica de la sociología hegemónica. La erradican porque disuelven las fronteras de los entes enfrentados y muestran su permanente heterorreferencia: alguien sólo es algo desde la perspectiva (figuracional) de otro, y viceversa. No es sustentable la disyunción tradicional Individuo $o$ Sociedad; sólo es plausible la conjunción de interdependencia Individuo $y$ Sociedad $^{44}$.

ción de Luis XIV como administrador del equilibrio de poder entre la burguesía y la aristocracia (Elias, 1982a: 226 ss.). Se agrega a ésta la idea de que el poder es un continuo en el que siempre hay que precisar el grado en que lo disfruta o sufre alguien. Y así insiste en que "pueden observarse grados diversos [...] de poder; [...] no existe ningún absoluto punto cero» (ibid.: 195). La última idea es que, en toda relación de dominación, el que domina está sometido a las reglas e instrumentos de su dominación y depende también, parcial pero significativamente, del dominado. Lo cual se muestra en el hecho de que «las coacciones que los grupos más poderosos ejercen sobre los menos poderosos vuelven a recaer sobre los primeros como coacciones de los menos poderosos y presiones para la autocoacción» (ibid.: 348); el ejemplo más característico sería el mecanismo de dominación de la etiqueta cortesana convertido en «un perpetuum mobile fantástico que nadie dirige» (ibid.: 121) y domina al mismo rey, su principal propulsor y beneficiario.

43 Se trata de una apreciación recurrente en los análisis eliasianos sobre la corte absolutista. El rey mantenía una relación ambivalente de poder frente a la nobleza: luchaba contra ella y a la vez era el garante de su conservación (Elias, 1982a: 202-203). Elias no particulariza esta situación, sino que la muestra como característica típica del proceso civilizatorio. Y así mantiene que hay «una especial cualidad de las relaciones humanas que también fue surgiendo con la creciente división de las funciones en la sociedad: su abierta o latente ambivalencia. Tanto en las relaciones interindividuales como en las relaciones entre diferentes estratos funcionales, se manifiesta una específica dualidad o incluso multiplicidad de intereses de forma tanto más marcada cuanto más amplia y densa sea la red de interdependencias. En tal caso todo el mundo, todos los grupos, estamentos o clases dependen en cierta medida los unos de los otros; son amigos, aliados o compañeros potenciales; y son al mismo tiempo oponentes, competidores y enemigos potenciales» (Elias, 1982c: 167).

${ }_{44}$ Elias insiste en que la superación de ese dualismo es el cometido central del concepto de figuración. Y, así, en sus análisis sobre la corte de Luis XIV propone: «la sociedad cortesana no es un fenómeno fuera de los individuos que la forman; los individuos que la constituyen [...] no existen fuera de la sociedad que integran unos con otros. El concepto de "configuración" sirve para expresar esta situación. El uso lingüístico habitual dificulta el hablar de individuos que conjuntamente forman sociedades, o de sociedades que están constituidas por individuos [...] Si uno utiliza palabras menos cargadas de connotaciones resulta más factible poder expresar lisa y claramente [...] que los hombres individuales constituyen conjuntamente configuraciones de diverso tipo o que las sociedades no son más que configuraciones de hombres interdependientes. Hoy en día se usa reiteradamente, en este contexto, el concepto de "sistema". Pero en tanto no se piense en los sistemas sociales como sistemas de hombres, sigue uno sin pisar tierra al usar este concepto» (Elias, 1982a: 31). 
Alcanzamos así el punto final de la reconstrucción de la alternativa figuracional propuesta por Elias en su lucha contra lo que he denominado ahistoricismo sustantivo de la sociología hegemónica. Esa alternativa no es desdeñable, pero, como ocurría anteriormente con su alternativa a la historiografía, habrá que calibrar también su justicia crítica y la solidez de su construcción.

En su justicia crítica no quiero demorarme. Se podría objetar a Elias que el fantasma que perseguía era un sueño ya desvanecido, que Parsons ya no reinaba cuando y cuanto él creía, que su retrato del estructural-funcionalismo era parcial y estaba deformado en rasgos fundamentales y, sobre todo, que al lado de la parsoniana había muchas otras tradiciones sociológicas que podría y debería haber tomado en consideración en su guerra contra el ahistoricismo temático y sustantivo de la sociología.

Todo esto, aunque sea relevante, me parece menor. Lo decisivo es lograr un balance final. Tras éste, se ha de concluir encomiando su lucha — durante tiempo a contracorriente- a favor de una sociología reorientada temáticamente hacia la historia, apreciando positivamente su esbozo de historización del aparato categorial de la sociología. Ciertamente, se trata de un esbozo que no consiguió nunca una elaboración teórica sistemática, tarea para la que tal vez Elias no estuviera especialmente dotado. Se lo impedían, además, los rasgos «decimonónicos» de su pensamiento: su epistemología básicamente positivista (aunque pasada por el diván psicoanalítico), la consecuente necesidad de fundamentar ontológicamente sus propuestas teóricas, su obsesión civilizatoria por el proceso de desarrollo de las coacciones y autocoacciones, etc. Pero el esbozo propuesto está ahí y merece ser tomado en consideración. Nos orienta a romper con el estatismo analítico, a tomar en cuenta la temporalidad, a la disolución de las aporías dualistas que tanto han empantanado la discusión sociológica, a una conceptualización compleja y matizada de las relaciones sociales como relaciones de poder. Y esas orientaciones han resultado eficaces o, por lo menos, premonitorias de desarrollos actuales de la sociología. Un caso relevante lo muestra la teoría de la estructuración, que, por lo menos en la formulación de Abrams (1982), parte de una lectura explícita de Elias y de la asunción de su programa de una historización temática y sustantiva de la sociología. Otro caso igualmente relevante lo muestra el desarrollo desde la década de los setenta de una sociología histórica que, aunque no sea eliasiana, sí asume implícitamente su programa.

Las consideraciones eliasianas sobre las deficiencias que arrastran la historia y la sociología y sus propuestas de reorientación teórica o metodológica tienen en su obra un estatuto subordinado. Son reflexiones y propuestas que surgen al hilo de sus estudios sobre un objeto inmediato privilegiado: el proceso de la civilización. A Elias le interesan los problemas discursivos en sus distintas 
variantes en razón tan sólo de los problemas sustantivos del acontecer histórico. Las consideraciones sobre la historia-disciplina o sobre lo que hoy denominamos sociología histórica son, así pues, residuos de sus propuestas sobre la historia-acontecer. Es éste el problema fundamental en el que centra su atención: la historicidad ${ }^{45}$ y su desarrollo temporal como proceso civilizatorio.

Historicidad y proceso de civilización son la cara general y particular de un mismo asunto: eso que en alguna ocasión llama el "problema general del cambio histórico" (Elias, 1982c: 230). Pues es este problema el que se hace inteligible a partir de una historicidad socialmente configurada y se materializa en ese proceso multisecular en pos de una creciente civilización. Como comprobaremos, la respuesta que la sociología ha de brindarle aúna la pertinencia cognitiva y la relevancia práctica: lo disuelve al hacerlo inteligible (narrable y explicable) y lo reorienta al anunciar una intervención práctica esclarecida.

¿Cuál es ese problema general del cambio histórico? ¿Existe alguna formulación sintética que permita retratarlo? La respuesta a estas preguntas aparece en lo que constituye un tema recurrente en la obra de Elias: aquel en el que se aborda lo que paso a denominar la forma general del desarrollo histórico. Entiendo por ésta la forma que a lo largo de la historia adquiere el cambio con independencia de sus contenidos particulares e historiográficamente singulares. Se trata, pues, de una forma que aparece en todos los procesos de cambio histórico, aunque se muestra de manera especialmente nítida en el proceso civilizatorio.

Para retratarla, Elias no escatima aproximaciones. En una de sus manifestaciones más sintéticas aparece así retratada: «En su conjunto este cambio no está planeado "racionalmente"; pero tampoco es un ir y venir azaroso de pautas desordenadas» (Elias, 1982c: 230). En otras formulaciones sintéticas especifica que se trata de «una sucesión impersonal y en buena parte autorregulada de sucesos orientados en una dirección» o "un proceso [...] simultáneamente ordenado y estructurado e involuntario y no planeado» (Elias, 1982b: 179). Su retrato alcanza el máximo de intensidad dramática cuando Elias (1990a: 84) recurre a la poesía y, en dos versos, la presenta como la forma de un proceso «nacido de planes, pero no planeado / movido por fines, pero sin un fin».

Es esta forma la que define el problema general del cambio histórico y abre la investigación sobre la historicidad y esa concreta manifestación suya que es el desarrollo civilizatorio. Es la forma de aquello que siendo "ciego" (Elias, 1982c: 232) se desarrolla en una dirección determinada; un cambio que nadie busca y todos encuentran al buscar algo diferente; un proceso que transcurre constrictivamente y no responde a constricción natural alguna; y que parece guiado por una intención que no es intención alguna. Proceso que, se nos ase-

45 Elias no habla de historicidad, pero este concepto retrata bien el problema que aborda, pues su tarea no es tan sólo la de dar cuenta de un proceso histórico privilegiado, el desarrollo civilizatorio, sino de reconstruir el formato general del desarrollo histórico y, consecuentemente, de la historicidad como capacidad social-humana de constituir la historia. Cfr. la voz «historicidad» en Ferrater (1979). 
gura, «no es, en absoluto, algo enigmático» (Elias, 1982b: 177), a pesar de las paradojas que se acumulan al describirlo. Y no es enigmático porque su forma puede ser fijada nítidamente: es la propia de los procesos figuracionales dominados por las consecuencias no intencionales de la acción intencional.

En esto consiste el diagnóstico de Elias y con él proporciona la clave para hacer inteligible la historicidad humana. La historia es posible y adquiere su peculiar forma de desarrollo porque de las acciones intencionales de los hombres se desprenden consecuencias que no estaban en la intención de nadie pero que todos, al actuar siguiendo sus particulares intenciones, han contribuido a produ$\operatorname{cir}^{46}$. El enigma de la direccionalidad resultante abocaría a la pura ensoñación filosófica si no se pudieran hacer inteligibles las relaciones entre las intenciones frustradas y las consecuencias emergentes. Esa inteligibilidad la proporciona «la relativa autonomía de las figuraciones sociales»(Elias, 1982c: 231), que permite explicar cómo las acciones intencionales no dominan sus consecuencias y cómo éstas son direccionales a pesar de no cumplir plan intencional alguno.

El diagnóstico eliasiano conecta con la tradición. Es, en realidad, un eslabón más en la larga cadena de un multisecular esquema descriptivo ${ }^{47}$ que viene subrayando la presencia de un hilo de desarrollo histórico o mano providente que, como sostenía ya Vico (1985, I: 104), "de las pasiones de los hombres, todas ellas dirigidas a su utilidad privada, por las cuales vivirían como bestias fieras en la soledad, ha hecho los órdenes civiles por los que viven en una sociedad humana». Se trata de un esquema descriptivo que llega hasta nuestros tiempos y que no puede ser interpretado como un fósil contemporáneo de la obsoleta filosofía de la historia cristiana, ilustrada o posilustrada ${ }^{48}$. Su virtud

${ }^{46}$ En una de sus formulaciones más sistemáticas, el diagnóstico aparece así: «los planes y las acciones, los impulsos emocionales y racionales de los individuos se entremezclan continuamente en forma hostil o amistosa. Este entramado [tissue] básico que resulta de los múltiples planes y acciones individuales de los hombres puede dar lugar a cambios y pautas que ninguna persona individual ha planeado o creado. De esta interdependencia de la gente surge un orden "sui generis", un orden mucho más compulsivo y fuerte que la voluntad y la razón de los individuos que lo componen. Es este orden que entrama impulsos y afanes humanos, este orden social, el que determina el curso del cambio histórico» (Elias, 1982c: 230; énfasis N. E.).

${ }^{47}$ Entiendo, en este contexto, por esquema descriptivo una fórmula sintética (en este caso: consecuencias no intencionales de acciones intencionales) que permite dar cuenta del decurso histórico en términos narrativos (qué va ocurriendo en la historia), retóricos (qué enseñanzas nos proporciona esa descripción del acontecer) y/o analíticos (qué lo hace inteligible y explicable). De la mano de ese esquema descriptivo se asienta, pues, la narrativa, la retórica y la analítica de la no intencionalidad histórica.

${ }^{48}$ En efecto, ese esquema de descripción histórica que, como se acaba de comprobar, está ya claro en Vico tiene continuidad en la filosofía ilustrada (Kant) y posilustrada (Hegel) de la historia y se ramifica en las distintas corrientes de la ciencia social del XIX y el XX, pasando por Tocqueville, Marx, Weber, Durkheim y Simmel hasta llegar a la sociología histórica contemporánea (Tilly, Mann). No se trata, pues, de un esquema propio de la filosofía de la historia, ya que aparece en las obras que le son programática y realmente más hostiles. Es, además, un esquema que se asienta también en la economía política clásica en la forma del teorema de la mano invisible. En este caso su función no consiste en historizar, sino en naturalizar el objeto de su indagación (cfr. Bilbao, 1993). 
radica en permitir procesar la forma inmediatamente paradójica del desarrollo histórico, haciéndola comprensible y asible gracias a la utilización de diversas estrategias narrativas y analíticas de la mano de retóricas pragmáticamente eficaces. Lo que habrá que averiguar es cómo se concretan en el caso específico de Elias las estrategias narrativas y analíticas y su complemento retórico.

Comenzaré por la estrategia analítica. Elias es consciente de pisar un terreno pantanoso: en concreto, el gran pantano de Hegel. De ahí que sus formulaciones tan hegelianas ${ }^{49}$ sobre los individuos intencionales que generan un mundo no intencional pero lleno de sentido vayan seguidas de advertencias y cautelas. Y así advierte que ese orden direccional de la historia no es ni racional ni irracional; no es producto ni de una naturaleza sabia ni de un espíritu astuto (Elias, 1982c: 231). Es simplemente producto de la mediación figuracional de las interdependencias humanas o, más estrictamente, «la consecuencia del entramado de acciones de muchos hombres interdependientes» o de "su dinámica constrictiva» (Elias, 1982c: 177, 160). Deja, pues, de ser enigmático cuando se toma en consideración el entramado figuracional en el que surge: su relativa autonomía y su dinamismo propio.

Para proceder en ese sentido hay que atender a la historia concreta y analizar figuracionalmente cómo se han generado específicos cambios sociales. Es evidente que, para Elias, los más relevantes son los ligados al proceso civilizatorio. De ahí que en ellos centre su atención.

Desde un punto de vista global, la civilización es un producto del desarrollo histórico que se materializa en cambios profundos en el entramado de las coacciones humanas (paso de la heterocoacción a la autocoacción) y cuyas causas últimas radican en un triple proceso de incremento de la diferenciación, la división funcional y la interdependencia (Elias, 1982c: 233) ${ }^{50}$. Analizado desde un

49 Compárense los siguientes textos de Hegel y Elias y se comprobará su estricta similitud. Donde Hegel (1980: 85) dice: «en la historia universal y mediante las acciones de los hombres surge algo más de lo que ellos se proponen y alcanzan, algo más de lo que ellos saben y quieren inmediatamente. Los hombres satisfacen su interés; pero al hacerlo, producen algo más, algo que está en lo que hacen, pero que no estaba en su conciencia ni en su intención», Elias (1982c: 160), por su parte, sostiene: «del entramado de innumerables intereses e intenciones individuales - ya tiendan en la misma dirección, ya en direcciones hostiles y divergentes - surge algo que no fue planeado ni buscado por ninguno de esos individuos, pero que, con todo, emerge de sus intenciones y acciones».

${ }^{50}$ Como es notorio, el esquema explicativo de Elias pretende dar cuenta, a la vez, de la psico y sociogénesis de la civilización. En su formulación más general, ese esquema adopta enunciados inequívocamente durkheimianos, teñidos por un "rankeanismo» decimonónico que enfatiza la relevancia del Estado. Un texto que recoge las pretensiones y la curiosa síntesis de Durkheim y Ranke es el siguiente: «el proceso de civilización, visto desde la perspectiva de los modelos de conducta y control de los impulsos, es la misma tendencia que, vista desde la perspectiva de las relaciones humanas, aparece como el proceso de progresiva integración, aumento de la diferenciación de las funciones sociales y de la interdependencia, y la formación de unidades de integración cada vez más amplias de cuya fortuna o movimientos depende el individio, lo sepa o no» (Elias, 1982c: 88). Esas unidades de integración cada vez más amplias son las estructuras políticas o Estados en las que Elias centra su atención en El proceso... y La sociedad cortesana. 
punto de vista más concreto y en contacto con la evidencia historiográfica, ese proceso es inteligible como la consecuencia no querida de acciones humanas sometidas a lo que Elias denomina «mecanismos» figuracionales. En este sentido se desarrollan los análisis de El proceso... y La sociedad cortesana. El énfasis cae sobre mecanismos figuracionales específicos: el mecanismo de la feudalización (Elias, 1982c: 15 ss.), el mecanismo del monopolio (ibid.: 104 ss.), el mecanismo real (ibid.: 161 ss.) o el mecanismo de la etiqueta cortesana (Elias, 1982a: 107 ss.). Son éstos los que explican sociológicamente las situaciones históricas y sus transformaciones no intencionales hacia una civilización creciente.

El concepto de mecanismo figuracional no recibe una sistemática especificación teórica; Elias se limita a utilizar la metáfora ${ }^{51}$, aclarándola al hilo de su utilización. Por mecanismo habría que entender un específico entramado de interdependencias que, aunque no determine cerradamente, sí configure un «alto grado de probabilidad» (Elias, 1982c: 99) al desarrollo de específicos procesos sociales. Esos procesos pueden ser de muchos tipos: procesos bloqueados que desembocan en un clinch $^{52}$, procesos cíclicos ${ }^{53}$ o procesos de cambio direccional y acumulativo ${ }^{54}$. Por medio de ellos se hacen inteligibles las diferentes situaciones de interdependencia (procesos reproductivos), pero también las dinámicas históricas de cambio. La dinámica civilizatoria, en concreto, es explicada como el producto de cambios en las condiciones que permiten operar al mecanismo de feudalización, poniendo en crisis su ciclo de centralización/descentralización. Tales cambios crean una situación que permite que el mecanismo del monopolio opere, lo que desemboca, con el surgimiento de la sociedad cortesana, en una figuración social dominada inmediatamente por dos mecanismos muy específicos aunque ensamblados, el real y el ceremonial. A su vez, estos mecanismos se sitúan en la génesis de la crisis revolucionaria de $1789^{55}$.

${ }^{51}$ Probablemente, Elias adoptó esta metáfora del lenguaje de la corte de Luis XIV, específicamente de St. Simon, quien en sus Memorias hablaba de "la mécanique» real: la colosal eficacia social (en términos de asignación de poder y prestigio) del más mínimo gesto del rey. Cfr. Elias (1982a: 179).

52 De este tipo son los mecanismos que Elias denomina «mecanismo real» (Elias, 1982c: 171) y perpetuum mobile de la etiqueta (Elias, 1982b: 118 ss.). El primero es un mecanismo más amplio que engloba al segundo. Característico de ambos es dar lugar a un proceso bloqueado de equilibrio (ni se retrocede ni se avanza) dominado por la ambivalencia (sin compromiso ni conflicto definitivos). El bien social que procesan esos mecanismos puede ser el monopolio fiscal y militar o el prestigio. Sobre el concepto de $c l i n c h$, véase más adelante, nota 60 .

${ }^{53}$ Un tipo de proceso cíclico es el que genera el mecanismo de la feudalización (Elias, 1982c: 26-27), en el que se suceden procesos tímidamente centralizadores (ligados a la expansión bélica) y procesos descentralizadores (tras la consolidación de la conquista, la pacificación y el reparto del botín).

${ }^{54}$ El proceso direccional más nítido es el que surge del mecanismo de monopolio, que en su formulación más económica dice lo siguiente: «en una sociedad en la que existen [...] presiones competitivas, el que no gana un "más" automáticamente se convierte en un "menos" (Elias, 1982c: 98-99), lo que genera estructuralmente un proceso hacia la centralización de las coacciones. Para una definición sistemática, cfr. ibid.: 106.

${ }^{55}$ Los análisis sobre la crisis del mecanismo cíclico de la feudalización son realizados, de 
No entraré en una especificación mayor de la estrategia analítica que, recurriendo a la relativa autonomía dinámica de las figuraciones sociales, permite a Elias utilizar sociológicamente el esquema descriptivo de las consecuencias no intencionales. Ya ha quedado suficientemente especificada su tesis central, que asegura que las figuraciones median entre la intencionalidad humana y el mundo histórico, desvelando que tanto en las condiciones previas a la acción como en las consecuencias que de ella dimanan se afirma un mundo estrictamente no intencional dotado de eficacia histórica ${ }^{56}$.

La estrategia analítica va de la mano de una estrategia narrativa, aunque no creo que Elias fuera consciente de ello. Por estrategia narrativa entiendo aquella que permite convertir un conjunto heterogéneo de acontecimientos en una historia en la que la trama coliga, totaliza y tipifica el acontecer social ${ }^{57}$. Esta estrategia narrativa incorpora el esquema descriptivo de las consecuencias no intencionales configurándolo como una historia significativa y narrable.

Como es sabido, Hegel tradujo el esquema descriptivo de las consecuencias no intencionales a la trama narrativa de la astucia de la razón. De este modo, convirtió la historia universal, aparentemente vertebrada por el trágico sacrificio de la inocencia humana, en la comedia de la gran reconciliación y el Domingo final del Saber Absoluto ${ }^{58}$. Elias criticó el esquema narrativo de la astucia de la razón como "expresión urdida a tientas, soñando despierto" (Elias, 1990a: 83); pura ensoñación de filósofo. Y, en verdad, su trama narrativa es muy distinta; no porque prescinda de algún tipo de ensoñación, sino porque utiliza otra metáfora no menos potente. Y, así, lo que para Hegel es una historia atravesada por el ardid de la razón, es para él un desarrollo dominado por las inmediatas ironías del aprendiz de brujo. Esta metáfora, que está implícita en sus narraciones, llega incluso a hacerse explícita en alguna ocasión,

forma extensa, en el capítulo 1 del volumen II de El proceso... (Elias, 1982c: 13 ss.); los análisis sobre la dinámica civilizatoria gracias a los mecanismos del monopolio y real, en el capítulo siguiente (ibid.: 91 ss.); los análisis sobre el mecanismo de la etiqueta y la génesis de la crisis de 1789 aparecen más desarrollados en La sociedad cortesana (Elias, 1982a: caps. V, VI y IX).

${ }^{56}$ De aquí la doble crítica eliasiana a las aproximaciones sistémicas, que prescindirían de las intenciones de los actores, y a las aproximaciones en términos de teoría de la acción, que pretenderían reducir lo no intencional (de las situaciones previas y las consecuencias posteriores) a la intención de los actores (cfr. Elias, 1982b: 111; 1990b: 129).

${ }^{57}$ Esta formulación sintética resume las propuestas sobre la narratividad historiográfica de Ricoeur (1983) y White (1987). Por coligación entiendo un esquema conectivo que engarza los acontecimientos; por totalización, la conversión de un complejo heterogéneo de elementos en una totalidad (una historia; ej.: el proceso de la civilización); por tipificación, la conversión de lo narrado en un caso de una trama inmemorial que forma parte del acervo cultural del narrador y el lector de la historia.

${ }^{58} \mathrm{Y}$, así, la historia, que se muestra inmediatamente como «el ara ante la cual ha sido sacrificada la dicha de los pueblos, la sabiduría de los Estados y la virtud de los individuos", como un "enorme sacrificio», aparece al final atravesada y hecha significativa por un ardid de la razón que hace que «las pasiones obren por ella y que aquello mediante lo cual la razón llega a la existencia se pierda y sufra daño» (Hegel, 1980: 80, 97). Sobre la conversión hegeliana de la tragedia histórica en comedia de reconciliación, cfr. White (1987: 117 ss.). 
mostrando su idoneidad para hacerse cargo del entero desarrollo de la historia. Y, así, Elias propone que "los seres humanos se enfrentan una y otra vez ante el resultado de sus propias acciones como lo estaba el aprendiz de brujo ante los espiritus que evocó y que, una vez conjurados, escaparon a su control: contemplan con asombro los giros y desarrollos de la corriente histórica de la que ellos mismos forman parte, sin poder controlarla»(Elias, 1990a: 83; énfasis R. R.).

Una historia entramada en términos de aprendiz de brujo es una historia dominada por la ironía ${ }^{59}$. Pero la ironía sólo es el tropo lingüístico inmediato que permite poner en marcha la narración histórica; instrumento y punto de partida, pero no conclusión final. La historia, para Elias, no es una sátira insensata que muestre la falta de sentido de las sociedades humanas y su proceso de transformación. Puede, ciertamente, acabar por serlo, pero sólo en el caso de que los hombres, atenazados por el temor y la afectividad, se nieguen a aprender de esa magistra vitae y no procedan a controlar racionalmente las fuerzas que, de forma no intencional, han puesto en marcha. En definitiva, el aprendiz de brujo puede llegar a la madurez del brujo experimentado. De este modo, la ironía histórica se torna en fuente de conocimiento cara a una reconducción emancipatoria de lo histórico.

Para captar cabalmente esta reconfiguración narrativa de la historia hay que atender a la estrategia retórica en la que participa. Como ha mostrado Hirshman (1991), el esquema descriptivo de la no intencionalidad ha ido de la mano de distintas retóricas progresistas y reaccionarias. Las denominaré retóricas de la no intencionalidad. En ellas se ha de encontrar de qué modo la persuasión ejercida por un cierto relato introduce orientaciones pragmáticas específicas: esperanzas o desesperaciones ${ }^{60}$.

Si se atiende a lo que Elias cuenta y a las esperanzas prácticas que pone en ello, su discurso habría que situarlo a medio camino entre la retórica de la pru-

59 El aprendiz de brujo histórico se topa con frecuencia con la ironía de que sus intenciones no sólo se ven burladas por los hechos, sino que éstos le proporcionan lo inverso de lo que buscaba. Esta ironía extrema la encuentra Elias en la no intencionalidad de los procesos de cambio. «Es perfectamente posible — comenta Elias - que grupos de personas que en su disposición consciente traten de asegurar el mantenimiento y la preservación de la figuración existente, refuercen con sus actos precisamente las tendencias de cambio de ésta. Es igualmente posible que grupos de personas que busquen conscientemente el cambio, refuercen las tendencias a la permanencia de su figuración" (Elias, 1982b: 177-178). De aquí la frecuencia en la historia de alguaciles alguacilados por sí mismos.

${ }^{60}$ Entiendo la retórica al modo clásico, es decir, como arte de la persuasión que induce a actuar en un sentido determinado. Entiendo por retórica de la no intencionalidad aquella que se construye con orientaciones prácticas a partir de un material histórico que ha sido descrito como un caso de consecuencia no intencional de acciones intencionales. Hirshman (1991) analiza sólo parcialmente este tema, pero se puede partir de sus consideraciones para distinguir dos grandes tipos de retóricas de la no intencionalidad: a) la retórica conservadora o reaccionaria o de la prudencia, diversificada en retórica de la perversidad, la futilidad y el riesgo; $b$ ) la retórica progresista o del activismo paradójico, diversificada en retórica de la reconstrucción radical, de las leyes dinámicas de la historia y de la sinergia. Los distintos tipos parten de lo mismo (un desarrollo histórico no intencional) para inducir «recetas» prácticas distintas. 
dencia, característica del pensamiento conservador, y la retórica progresista, propia de la Ilustración, sus hijos y sus nietos.

En efecto, las consideraciones eliasianas sobre lo que primero llama clinch y más tarde doble vínculo ${ }^{61}$ conectan en su tono y mensaje con esa retórica de la prudencia que muestra las dificultades que los hombres tienen a la hora de orientar positivamente los procesos de cambio que aparentemente protagonizan pero en realidad sufren. Pues respondiendo emocionalmente a las situaciones que han engendrado de forma no intencional sólo consiguen incrementar la opacidad del mundo social en que viven. Desde este punto de vista, sólo cabe esperar que al anochecer emprenda su vuelo el búho de Minerva o que eso ocurra ya en una noche cerrada y polar en la que nada haya que hacer, sino lamentarse del cumplimiento de las desgracias anunciadas ${ }^{62}$. Las consideraciones de Elias sobre «la próxima guerra mundial» (1988) van en ese sentido.

Pero hay otro Elias, hijo al fin y al cabo de la Ilustración. Es el que presenta la historia como un proceso de aprendizaje; el que espera que los hombres que la han sufrido sean capaces de controlarla o, al menos, de adaptarse sabiamente a ella ${ }^{63}$. El clinch congelado y la esquismogénesis simétrica del doble vínculo serán disueltos gracias a una escalada de la reflexividad inducida y

${ }^{61}$ La imagen pugilística del clinch aparece ya en Sociología fundamental (Elias, 1982b: 34), pero es retomada y redefinida en Compromiso y distanciamiento como double bind, utilizando, se asegura, el concepto de Bateson reconvertido sociológicamente (Elias, 1990b: 66). Ambos intentan dar cuenta de una situación de círculo vicioso: ante una coyuntura de peligro, los hombres responden emocionalmente, lo que, a su vez, incrementa el peligro en que se vive, lo que genera nuevas respuestas emocionales, etc. (ibid.: 69, 127). En razón de esto, se cercena la posibilidad de aprender y surge una dinámica en espiral en la que las partes vinculadas responden en términos crecientemente emocionales a sus emociones enfrentadas (ibid.: 69). Que Elias presente un esquema así como double bind es, sin duda, producto de una lectura errónea de Bateson; son conceptos que poco tienen que ver. En realidad, el doble vínculo de Elias se asemeja más a la "esquismogénesis simétrica» de Bateson: responder siempre en términos de más de lo mismo, es decir, más emocionalmente a las emociones, más violentamente a la violencia, etc. (cfr. Bateson, 1985: 133 ss.).

62 Desde este punto de vista, el búho de Minerva que hace inteligible un mundo ya hecho es: a) o un búho de la anochecida, pues en todo estadio de desarrollo social «las personas implicadas en esos procesos continúan aferradas a sus actividades sociales de un nivel anterior" (Elias, 1990a: 244) y sólo al final engendran actitudes más adecuadas y realistas, o b) un búho de la noche cerrada que levanta su vuelo cuando ya es demasiado tarde y nada cabe aprender. En este sentido aparecen ecos del lamento de Casandra dramatizando el texto de Humana conditio: "no es un disparate suponer que después de una guerra nuclear la humanidad superviviente se sentirá más inclinada, a causa de la amarga experiencia sufrida, a crear instituciones efectivas para la solución pacífica de los conflictos internacionales» (Elias, 1988: 80); es evidente que será demasiado tarde.

63 Ese aprendizaje está ligado al proceso de civilización, ya que su dinámica propia, aunque opera "de forma ciega», genera ámbitos crecientes "para la intervención planificada tanto en las estructuras sociales como individuales —una intervención basada en un creciente conocimiento de la dinámica no planeada de esas estructuras» (Elias, 1982c: 232). La sociología surge en esos ámbitos y se ha de convertir en guía para la acción (cfr. Elias, 1982b: 214). El optimismo ilustrado y la ingeniería comtiana se conjugan en Elias, que también podría haber convertido en su divisa el "conocer para poder» de Comte. 
mediada por la sociología. Esta esperanza en «un autocontrol reflexivo» (Bogner, 1987: 272) genera la metáfora de «la escalera de caracol» que aparece en distintos textos eliasianos ${ }^{64}$. Nos propone la imagen de un ser humano no sólo capaz de mirar distanciadamente su recorrido histórico y reconocer en él la impronta no intencional dejada por las figuraciones, sino, además, capaz de observar su observación y controlar su control. Al final, la aventura del aprendiz de brujo se ha de tornar en una metaescalada reflexiva que haga posible que los hombres aprendan de la historia y accedan a un grado mayor de control sobre lo que en ella encuentran.

Concluyo ya este trabajo. Se ha visto la enorme relevancia en la obra de Elias de lo que genéricamente he denominado el problema de la historia, cómo surge de sus investigaciones sobre la forma general del desarrollo histórico y cómo alcanza soluciones que tienen importantes proyecciones en los campos disciplinares de la historia y la sociología. El resultado final es el esbozo de una sociología histórica, apuntalada teórica y metodológicamente y desarrollada en algunos campos estratégicos: la civilización y la sociedad cortesana.

Esa sociología ha de cumplir, además, una relevante tarea civilizadora. Elias siempre creyó que «el deber de la sociología es hacer que los hombres [...] se entiendan mejor a sí mismos y a los demás» (Elias, 1982a: 281) y, al contemplarse "desde un mayor distanciamiento" (Elias, 1982c: 325), consigan someter a su control los procesos históricos en los que están instalados. La esperanza es clara: el aprendiz de brujo, arrastrado por la dinámica autónoma de los mecanismos figuracionales, acabará por convertirse, gracias a la ilustración sociológica, en actor reflexivo. Sólo en tal caso cabrá esperar que, como se sueña en el poema de Elias que encabeza este trabajo, llegue a "cabalgar la tormenta» de desorden y sinsentido que lo arrastra.

${ }^{64}$ La imagen se construye así: «los seres humanos poseen la capacidad de saber que saben; son capaces de reflexionar sobre su propio pensamiento y de observar qué y cómo observan. Pueden, bajo determinadas condiciones, subir un peldaño más y verse a sí mismos como seres que saben, tener conciencia de que saben de ellos mismos que son seres que saben. Dicho en otras palabras, son capaces de subir por la escalera de caracol de la conciencia de un piso, del que hay una vista específica, a otro, del que hay otra vista concreta, y, simultáneamente, pueden mirar hacia abajo y verse a sí mismos detenidos en otros niveles de la escalera de caracol» (Elias, 1990a: 125; cfr. también Elias, 1982a: 324-325). La imagen eliasiana es un poco a lo Escher: un caminante que se contempla a sí mismo subiendo. Supone, por un lado, un distanciamiento que rompe la lógica del compromiso propia del doble vínculo y, por el otro, un desdoblamiento de sí mismo de forma que se haga viable la autotematización. 


\section{BIBLIOGRAFIA}

Аввот, A. (1992): «From causes to events. Notes on narrative positivism», Sociological Methods and Research, 20 (4): 428-455.

Abrams, P. (1982): Historical Sociology, Sommerset, Open Books.

Barel, Y. (1989): La paradoxe et le système, Grenoble, Presses Universitaires de Grenoble.

Barraclough, G. (1983): «El proceso civilizador», Revista de Occidente, 20: 115-121.

BAteson, G. (1985): Pasos hacia una ecología de la mente, Buenos Aires, Carlos Lohlé.

Bauman, Z. (1979): "The Phenomenon of Norbert Elias», Sociology, 13 (1): 117-125.

BÉJAR, H. (1991): «La sociología de Norbert Elias: las cadenas del miedo», REIS, 56: 61-82.

BilbaO, A. (1993): «Hobbes y Smith: política, economía y orden social», Revista Española de Investigaciones Sociológicas, 61: 127-144.

Bogner, A. (1987): «Elias and the Frankfurt School», Theory, Culture and Society, 4: 249-285.

Bourdarias, F. (1991): «Norbert Elias: les techniques du regard», Sociétés, 33: 253-260.

Braudel, F. (1980): La historia y las ciencias sociales, Madrid, Alianza.

Dunning, E., y Elias, N. (1986): Quest for Excitement: Sport and Leisure in Civilizing Process, Oxford.

Elias, N. (1978): The Civilizing Process. Vol. I: The History of Manners, New York, Urizen Books.

- (1982a): La sociedad cortesana, México, FCE.

- (1982b): Sociología fundamental, Barcelona, Gedisa.

- (1982c): The Civilizing Process. Vol. II: Power and Civility, New York, Pantheon Books.

- (1987a): La soledad de los moribundos, México, FCE.

- (1987b): «The Retreat of Sociologist into the Present», Theory, Culture and Society, 4: 223-247.

- (1987c): "The Changing Balance of Power between the Sexes -A Process-Sociological Study: The Example of the Ancient Roman State», Theory, Culture and Society, 4: 287-336.

- (1987d): "On Human Beings and Their Emotions: A Process-Sociological Essay», Theory, Culture and Society, 4: 339-361.

- (1988): Humana conditio, Barcelona, Península.

- (1989): Sobre el tiempo, Madrid, FCE.

- (1990a): La sociedad de los individuos, Barcelona, Península.

- (1990b): Compromiso y distanciamiento, Barcelona, Península.

- (1991a): The symbol theory, London, Sage Publ.

- (1991b): Mozart. Sociología de un genio, Barcelona, Península.

Featherstone, M. (1987): "Norbert Elias and Figurational Sociology», Theory, Culture and Society, 4 (2-3): 197-211.

Ferrater, J. (1979-81): Diccionario de filosofía, Madrid, Alianza.

GRIFFIN, L. (1992): «Temporality, events and explanation in historical sociology: an introduction", Sociological Methods and Research, 20 (4): 403-427.

Hegel, G. W. F. (1980): Lecciones sobre la filosofia de la historia universal, Madrid, Alianza.

Hirshman, A. O. (1991): Retóricas de la intransigencia, México, FCE.

Kilminster, R. (1991): «Editor's Introduction», en N. Elias, The Symbol Theory, London, Sage Publ.: VI-XV.

LASCH, C. (1985): «Historical Sociology and the Myth of Maturity. Norbert Elias's "very simple formula"", Theory and Society, 14 (5): 705-721.

Le Goff, J., y NorA, P. (eds.) (1978-80): Hacer la historia, 3 vols., Barcelona, Laia.

Mann, M. (1991): Las fuentes del poder, I, Madrid, Alianza.

Martins, H. (1992): «Tiempo y teoría en sociología», en R. Ramos (comp.), Tiempo y sociedad, Madrid, CIS: 183-242.

Parsons, T. (1966): Societies. Evolutionary and Comparative Perspectives, Englewood Cliffs (NJ), Prentice-Hall.

RAmOS, R. (1993): «Problemas metodológicos y textuales de la sociología histórica», Revista Española de Investigaciones Sociológicas, 63: 7-28. 
Ricoeur, P. (1983): Temps et récit, Tome I, París, Seuil.

Skocpol, T. (ed.) (1984): Vision and Method in Historical Sociology, New York, Cambridge University Press.

Smith, D. (1991): The Rise of Historical Sociology, Cambridge, Polity Press.

STONE, L. (1986): El pasado y el presente, México, FCE.

VICO, G. (1985): Ciencia nueva, I y II, Barcelona, Orbis.

White, H. (1987): Metahistory, Baltimore, Johns Hopkins Univ. Press.

Zaret, D. (1980): «From Weber to Parsons and Scutz: The eclipse of history in modern social theory», American Journal of Sociology, 685 (5): 1180-1201.

\title{
RESUMEN
}

En Elias se puede encontrar un significativo precedente de la sociología histórica. Desde esta perspectiva, el artículo se centra en el triple problema de la historia en su obra: la crítica de la historiografía tradicional; la crítica de la sociología hegemónica ahistórica; la indagación sobre el desarrollo de la historia como proceso no intencional. Se concluye mostrando la triple estrategia (analítica, narrativa y retórica) de Elias para dar cuenta de este último problema.

\begin{abstract}
In Elias a significant precedent to historical sociology can be found. From this angle, the article is centered in a threefold problem of history in his work: the criticism of traditional historiography; the criticism of hegemonic unhistoric sociology; the investigation of the development of history as a unintentional process. The conclusion shows Elias' threefold strategy (analytical, narrative and rhetorical), reporting on this last problem.
\end{abstract}

